\title{
TERAPIA SEXUAL E INCLUSÃO SOCIAL
}

\author{
Maria do Carmo Andrade-Silva ${ }^{l}$
}

As formas mais especificas de terapia sexual surgiram na década de 60 , no bojo das várias mudanças sociais que aconteceram nessa época. No núcleo desta revolução de costumes, encontrava-se a inversão ideológica do conceito de Sexo - Reprodução para Sexo - Prazer.

Alteração a princípio de uma simples palavra, porém, a representação do rompimento de um verdadeiro dique, que durante séculos, conteve uma infinidade de valores, normatizações, pecados e injúrias graves, degenerações, perversões e desvios psicopatológicos. Portanto, enquanto tempo histórico, somos muito jovens para assimilar tamanha reformulação, como esta, que integra a nova representação sócio-sexual que envolve o conceito, Sexo - Prazer.

Alterações em códigos de valores morais, tão enraizados como os que compunham a idéia milenar, de que sexo tem, como objetivo, a reprodução, por mais que desejada e aplaudida, sofre interferência das emoções primariamente constituídas, que se debatem e se chocam com as novas necessidades, originando conflitos entre o que devo ou quero ser e o que consigo ser ou demonstrar.

\footnotetext{
' Psicóloga, Mestre em Psicologia e Livre-Docente em Sexualidade Humana; Coordenadora e Professora do Curso de Mestrado em Sexologia Universidade Gama Filho. Endereço para correspondência : Mestrado em Sexologia da UGF, Rua Manoel Vitorino, 553 - Prédio AR, $5^{\circ}$ andar, Piedade, CEP: 21740-900 - Rio de Janeiro, e-mail:messex@ugf.br
} 
Em função disso, uma série de novas angústias, doenças, conflitos, insatisfações e inadequações intra e interpessoais, têm emergido constituindo-se nas diversas queixas sexuais e conflitos conjugais, que rondam psicólogos e médicos, independentemente de suas áreas de atuação.

Poucos de nós, oriundos da mesma sócio-história, tivemos interesse e flexibilidade pessoal para atualizar-nos e preparar-nos especificamente para o trabalho com tais questões. Questões que exigem visão ampla e interdisciplinar, na medida em que ultrapassaram - e muito - o limite biológico e que interagem também com a esfera psicossocial, constituindo o conceito de prazer.

Sexualidade é algo muito mais amplo que coito, e mesmo a própria atividade coital, no ser humano, contém representações simbólicas pessoais, muito mais extensas que o simples ato de penetração de um pênis em uma vagina. As características pessoais, as representações simbólicas e a comunicação interpessoal, próprias a cada interação, é que dão o colorido personalizante que caracteriza e diferencia cada ser humano envolvido em um encontro sexual específico.

As pessoas fazem sexo por diversas motivações e estas encontram eco em necessidades: reprodutivas, eróticas, de orgasmo, prazer, por minimização de carências afetivas, obrigações, ganhos econômicos, etc...

Também as formas ou freqüências com que estas interações ocorrem variam de pessoa para pessoa e em diferentes momentos da vida de cada um. Não se admitindo limites estreitos ou normatizações generalizantes, enquanto necessidades ou formas de prazer de cada um, desde que estejam respeitados todos os direitos dos outros.

Ouvimos constantemente a máxima dos principios éticos em relação ao ser humano: o direito à vida. Porém, é preciso consciência de que este direito transcende e muito ao fenômeno biológico de existir. Implica, 
necessariamente, o exercício de outros direitos, que propiciam um minimo de condições para esta vida.

Além do atendimento às necessidades básicas de comer, beber e dormir, o ser humano, por constituir-se em um ser de relações, tem necessidades de expressão, de contato, de interação social, afetiva e sexual. E para o atendimento a estas necessidades, é preciso que tenha direitos a uma interação afetiva primária, à saúde e à educação. "Estudos com orientações mais biológicas, apontam que as experiências iniciais da vida, caracterizadas pelo contato físico, têm demostrado ser este um elemento necessário para o desenvolvimento e fundamentalmente para a manutenção do sistema nervoso central". (Nicolelis, M. A, de Oliveira, L. M. Lim, R. C. e Chapin, J. K. 1999 apud Manual de Promoção da Saúde Sexual - OMS e OPS. 2000).

Os direitos humanos constituem um processo inerente aos seres humanos, embora o reconhecimento destes direitos não os crie, por si só. "0 reconhecimento dos direitos sexuais encontram-se em processos de evolução. Os direitos humanos são princípios considerados universalmente como protetores da dignidade humana e promotores da justiça, igualdade, liberdade e direito à própria vida. Em função do direito à saúde ser um dos direitos fundamentais do ser humano, é óbvio que a saúde sexual também leve aos direitos sexuais". (Promoção da Saúde Sexual da OMS e OPS. 2000 pg 10).

"A saúde sexual é observada nas expressões livres e responsáveis das capacidades sexuais, processos que propiciam bem-estar pessoal e social harmonioso, enriquecendo a experiência de vida. Portanto, não se trata simplesmente de ausência de disfunção ou doença. Para que se possa usufruir de saúde sexual, torna-se necessário que os direitos sexuais sejam reconhecidos e garantidos" (0p. cit. Pg 06).

Os Direitos Sexuais elencados pela Associação Mundial de Sexologia (WAS), são: liberdade sexual, autonomia e integridade sexual do corpo, 
privacidade sexual, eqüidade de direitos, direito ao prazer sexual, à expressão afetiva e sexual, à associação sexual livre, à decisão reprodutiva livre e responsável, à informação baseada em conhecimentos científicos, à educação sexual integral e à atenção "a saúde sexual” (op. cit. Pg. 11).

As preocupações com os problemas que afetam a saúde sexual manifestam-se toda vez que as situações de vida, relacionadas com a sexualidade, possam afetar a saúde sexual e compreendem, portanto, situações que necessitem intervenção de pessoas ou da própria sociedade. E dentre estas, relacionam-se as seguintes situações: aquelas relacionadas à integridade corporal e sexual, as relacionadas com as expressões de erotismo, com as questões de gênero, com as orientações sexuais, com vinculos afetivos e com a reprodução.

Dentre os principais blocos de preocupação em relação à saúde sexual, observam-se: a reprodução, a pandemia do HIV/AIDS, a violência sexual e as disfunções sexuais.

Em nosso país, observamos principalmente efetivadas:

-A preocupação e a atenção à saúde reprodutiva. Quando, em função do foco sobre métodos contraceptivos e necessidade de planejamento familiar, desenvolveu-se uma série de campanhas educativas neste sentido, providenciou-se a implantação e implementação de postos de atendimento, promoveu-se à distribuição de contraceptivos, capacitouse profissionais para este tipo de trabalho especifico etc...

-A atenção às infecções causadas pelo HIV e conseqüente possibilidade do desenvolvimento da doença (AIDS). Tem tido bastante relevância, promovendo campanhas de prevenção ao virus, capacitando profissionais para estes atendimentos específicos, promovendo esclarecimentos aos doentes e orientações aos portadores do virus, etc...

Através dos trabalhos desenvolvidos nos tópicos anteriormente mencionados, uma série de comportamentos sexuais, pouco 
mencionados, precisa vir à tona, em função de clarificação das mensagens das campanhas e êxito das mesmas. Com isso, novas reviravoltas sociais apareceram e, dentre elas, a conseqüência da vida sexual das adolescentes - a gravidez não planejada - , assim como a bissexualidade, a relação anal heterossexual, a masturbação como prática desejada enquanto sexo seguro, a infidelidade nos casamentos e o contágio do HIV, atingindo as famílias.

Enquanto as campanhas em relação à AIDS eram dirigidas às minorias sexuais, podiam ser claras e diretas; porém, quando atingiram a família, um dos pilares básicos do casamento foi atingido e, então, passou-se a pensar em como lidar com essa ambivalência. Como se pensar em infidelidade e contágio daquele com quem se está casado, se ama, se admira ou, às vezes até se está apaixonado? Defensivamente, é melhor não ouvir estas realidades, pois ativam sentimentos dificeis de serem admitidos, sendo esta uma das grandes dificuldades de efetividade das campanhas.

Com o amadurecimento dos trabalhos em saúde reprodutiva e preventiva de HIV, transparece de forma clara, porém óbvia, a necessidade de desenvolvimento de processos de educação sexual mais amplos, com maior extensão e continuidade. Assim, em 1998, o Ministério da Educação inseriu, nos Parâmetros Curriculares Nacionais, a atenção aos temas transversais e, dentre estes, a orientação sexual, como uma nova proposta a ser implementada nas escolas de ensino fundamental desde as primeiras séries. Processo ainda em desenvolvimento, em função da falta de um preparo minimo para os professores e resistências pessoais de alguns para lidar com temas sexuais.

Outro fator, que já tem recebido alguma atenção, são as questões quanto à violência de gênero e os abusos e explorações sexuais infanto-juvenis. Delegacias especializadas, assim como trabalhos conjuntos entre o Ministério da Justiça e Organizações não Governamentais, como a ABRAPIA, têm promovido e desenvolvido campanhas de incentivo a denúncias, esclarecimentos à população e apoio às crianças e jovens explorados. 
No que se refere especificamente à terapia Sexual, sua real inclusão, enquanto estratégia de saúde pública, deixa muito a desejar. Apesar de a literatura internacional mencionar os problemas sexuais como queixas de alta incidência, em nosso país, a aceitação dos problemas sexuais, como problema de saúde, ainda á fato incipiente.

Nos USA, notificou-se uma prevalência de problemas sexuais em 43\% das mulheres e 31\% dos homens. (Laumann, E. O, Paik, A e Rosen, R. C. - 1999 apud. Doc. OMS - OPS 2000).

Em pesquisa realizada por Abdo, C. H. N. e Col (2002), em nosso pais, com uma amostra geral de 2.835 indivíduos com mais de 18 anos, relata-se que: entre as mulheres, a disfunção mais referida foi a falta de desejo (34.6\%), seguida pela disfunção orgásmica (29\%), enquanto entre os homens, quando computadas todas as classificações em relação à disfunção erétil, (leve, moderada e severa) observou-se um percentual de (46\%). E, quando computados somente os casos de Ejaculação Precoce, mencionados com freqüência alta, este percentual ficou em (15\%), porém, se somados todos os graus de dificuldade em relação à premência ejaculatória, este problema alcançou 56.8\% dos relatos.

No ambulatório do Mestrado em Sexologia da Universidade Gama Filho, no setor de Reprodução Humana do Instituto de Ginecologia da UFRJ, a avaliação dos últimos dois anos tem apontado que as queixas mais referidas, quando da triagem dos pacientes, têm se apresentado associadas: para as mulheres, as mais freqüentes têm sido a inibição ou diminuição de desejo sexual, associada à anorgasmia, enquanto, para os homens, a associação tem se apresentado entre ejaculação precoce e disfunção erétil.

Observa-se que os indices em relação à incidência ou prevalência das disfunções e/ou problemas sexuais, na literatura, são bastante variáveis e tais fatos apontam, especialmente, para as formas de avaliações e análises dos dados, assim como para os diferentes grupos amostrais estudados, não permitindo, portanto, generalizações conclusivas. No 
entanto, mesmo com todas as limitações apresentadas pelos diversos estudos, todos apontam para insatisfações e queixas sexuais freqüentes.

Em nosso meio, as temáticas sexuais têm sido bastante exploradas pela mídia e, dentre os modismos na área, temos a cobrança quanto à expressão de desejo sexual, que passa a ser exigida do casal contemporâneo. Se o desejo diminui, a preocupação torna-se evidente: o casamento acabou, existe alguém interferindo, não sou mais erótica (o) para ele (a). 0 mundo social cobra desejo e erotismo e as pessoas sentem-se pressionadas a se enquadrarem no ritmo "ideal e normal", como se possivel fosse um enquadramento para o desejo.

Das mulheres, passou-se a esperar, no minimo, um orgasmo durante a relação sexual e, hoje, a obrigação de tê-los, o que determina sua saúde sexual. Com estas novas exigências, temos visto proliferar uma "parafernália de tipos de orgasmo", que variam dos tradicionais clitorianos e vaginais aos do ponto G, útero axial, anal, telefônico, virtual, transcendental etc. Orgasmo é uma funcionalidade real e prazerosa para as mulheres, mas que, durante séculos de repressão, não pode ser naturalmente experenciado por elas. Mas não pode ser revertido em uma nova "tirania", como a exigência e obrigatoriedade de tê-los sempre e de preferência de forma múltipla, conforme é propagado pela mídia. Não atingir tais ideais tem se constituido em um novo fator desencadeante de inferiorização e inadequação sexual femininas.

Dos homens, passou-se a exigir controle ejaculatório, na medida em que a relação deve ser satisfatória para ambos, e não mais só para ele. A ejaculação rápida, que antes era sinônimo de virilidade e potência erótica, passou a constituir-se um problema de disfunção. A nova ideologia cobra ereção duradoura, pretendendo não só a maior possibilidade orgásmica feminina, como também o desfrute de mais tempo e qualidade de prazer para o próprio homem. Porém, a exigência de manutenção de ereção e controle ejaculatório, para alguns, não é prática fácil de ser obtida e a cobrança constante gera insegurança em 
função da sensação de incompetência, por não conseguir ser o que proclama o novo modelo de masculinidade, agora exigido dos homens.

A homossexualidade e a bissexualidade, orientações sexuais que variaram desde comportamentos esperados e até mesmo desejados, em determinadas épocas e culturas, passaram a constituir injúrias graves ou desvios psicopatológicos, até que, finalmente, em 1974, a Associação Americana de Psicologia decidiu retirar o homossexualismo do rol das doenças psiquiátricas. As discriminações estigmatizantes, contidas no imaginário social, no entanto, ainda persistem, rondando e marginalizando socialmente estas pessoas, que muitas vezes precisam de apoio, para a melhoria de sua auto-estima, para que possam viver em meio a tantas pressões sociais ainda subjacentes ou claramente discriminatórias.

Os que não conseguem - por algum dos motivos etiológicos biopsicosociais - vivenciar sua sexualidade de forma plena e prazerosa, sentem-se pressionados e marginalizados do mundo dos "normais". Tais percepções induzem o individuo a uma série de sentimentos de inferiorizações e desvalorizações, pois a constituição do conceito de ser, de uma pessoa, isto é, sua percepção de si mesmo, perpassa por sua sexualidade, e a vivência constante de uma inadequação sexual propiciará o desenvolvimento de outros tantos problemas pessoais e interpessoais.

Por sentir-se envergonhado e incompetente sexualmente, torna-se muitas vezes arredio e inseguro social e/ou conjugalmente. Processo que cria uma teia de raizes, atingindo vários setores da vida do indivíduo. Que vai encolhendo-se ou agredindo, cada vez mais, a si próprio ou a outros à sua volta, preservando muitas vezes seu "segredo", excluindo-se e oprimindo-se cada vez mais.

Os processos terapêuticos na área da sexualidade, além das dificuldades pessoais quanto à coragem para a tomada da decisão de procurar de ajuda, contam com outras sérias dificuldades como:

-A quem procurar? 
Há carência de profissionais conscientes que valorizem as queixas sexuais como problemas de saúde e que, enquanto tal, executem encaminhamentos adequados, quando tais queixas não forem de sua área de competência, e não aconselhamentos baseados em "achismos" ou em seus próprios códigos de valores morais.

Há carência de ambulatórios de serviço públicos específicos, com profissionais devidamente qualificados para o atendimento da população com queixas sexuais.

0 que temos, hoje, para o atendimento aos problemas sexuais, são, na maioria das vezes, serviços particulares, realizados por alguns poucos profissionais realmente capacitados para tal, mas aos quais a maioria da população brasileira não consegue acesso.

Os poucos serviços oferecidos à população, assim como o nosso ambulatório em hospital municipal, acontecem, de forma geral, como uma faceta de um projeto mais amplo, ou por deslocamento de funções, em alguns outros, onde os médicos e os psicólogos envolvidos não se encontram vinculados diretamente àquele serviço, mas sim ao empreendimento maior, que os contrata. Portanto, ainda na maioria dos casos, os ambulatórios de sexologia organizam-se por arranjos, impulsionados pelas motivações pessoais de alguns, que acreditam que os problemas sexuais infernizam a vida de muitas pessoas que já tem problemas demais, para que também tenham que viver excluidos da possibilidade de prazer. Um prazer cuja obtenção pode não lhes custar nada, ao menos no que se refere àquilo de que menos dispõem - dinheiro. É pela inclusão destas pessoas que temos trabalhado, apesar de todas as limitações enfrentadas, no Ambulatório de Sexologia do Hospital Moncorvo Filho.

Este serviço é vinculado à disciplina de prática de ambulatório em Sexologia do Mestrado da Universidade Gama Filho e funciona no Instituto de Ginecologia da UFRJ - Hospital Moncorvo Filho, por acordo institucional. Neste ambulatório trabalham, de forma integrada, médicos, 
psicólogos, professores e alunos do mestrado. Constitui-se, portanto, um sistema de acordos e trocas com todas as limitações deste tipo de processo. Não sendo, realmente, uma estrutura montada com o objetivo especifico de atendimento à saúde sexual, porém é o que dispomos e tem sido através dele que temos atendido às mais diversas queixas, que variam desde simples orientações e esclarecimentos, às diversas disfunções, mal formações, doenças, disforias de gêneros e conflitos conjugais.

É um local de vivência de muitas dificuldades e êxitos radiantes, reestruturações e adaptações de vários recursos técnicos à realidade de que dispomos; uma oportunidade de enriquecimento contínuo, através dos trabalhos interdisciplinares desenvolvidos e, principalmente, de aprendizado humanista, constantemente vivido através dos relatos simples de situações tão complexas, como as enfrentadas por estes nossos pacientes.

Apesar de tudo isso, este ambulatório de sexologia - e é de forma vaidosa que nos referimos a tal fato - foi o primeiro Centro de Atendimento aos Problemas Sexuais na cidade do Rio de Janeiro, tendo sido iniciado suas atividades em 1989. Tal empenho, é claro, só poderia ter sido concebido pela associação "quase sexual" de duas cabeças inquietas e briguentas socialmente, brilhantes congnitivamente e enlouquecidas emocionalmente, como as de Paulo Roberto Bastos Canella, doutor em medicina e livre-docente em ginecologia e de Araguari Chalar-Silva, mestre em psicologia e doutor em sexualidade humana.

Foi deste passo inicial que, nesta pequena incubadora, se fomentou e se acalentou, posteriormente, em alguns ex-mestrandos, a necessidade de brigar e procriar este tipo de atendimento público social. E, enquanto nossos filhotes, constituiram-se, recentemente, através do empenho pessoal de Círia T. Pinto, médica do serviço de climatério e menopausa do Hospital Antônio Pedro em Niterói, uma extensão para o atendimento aos problemas sexuais femininos naquela unidade e, enquanto médica da UERJ, Regina Moura, com sua empolgação e inquietação, brigou 
muito e conseguiu, junto com Jacqueline Ferreira e Márcia Aragão, psicólogas também funcionárias da UERJ, estruturar um serviço de sexologia vinculado àquela Universidade.

Todo início é difícil, especialmente quando se trata de sexo. Os medos, as desconfianças e a pouca seriedade com que nossos próprios colegas de profissão tratam o tema, é a constante enfrentada. 0 desânimo, muito vezes, bate à nossa porta, principalmente quando envolvidos com todos os limites de um serviço público para uma clientela de excluidos. Porém, sabemos que este é o caminho de todos os que nos precederam, e levaram a sério, o estudo clínico da sexologia. Portanto, não seria em nosso país que isto seria diferente.

“0 prazer erótico é uma dimensão do ser humano que, com freqüência, tem sido negado como necessidade fundamental, positiva, gratificante e promotora de saúde. Porém, estudos muito recentes demonstraram que a experiência erótica tem conseqüências até mesmo no plano fisiológico". (Komisaruk, B. R. e Whipple, B. 1998, apud. Manual para a Saúde Sexual. OMS. OPS. 2000, pg. 25) 